\title{
Thoraco lumbar spinal tuberculosis-assessment of functional outcome following posterior decompression and posterior instrumentation
}

\author{
Shanmuga Sundaram Pooswamy, Niranjanan Raghavn Muralidharaogpalan*
}

Department of Orthopaedics, Saveetha Medical College Hospital, Tamil Nadu, India

Received: 23 August 2018

Revised: 04 December 2018

Accepted: 06 December 2018

\section{*Correspondence:}

Dr. Niranjanan Raghavn Muralidharaogpalan,

E-mail: nir.rag@gmail.com

Copyright: (c) the author(s), publisher and licensee Medip Academy. This is an open-access article distributed under the terms of the Creative Commons Attribution Non-Commercial License, which permits unrestricted non-commercial use, distribution, and reproduction in any medium, provided the original work is properly cited.

\section{ABSTRACT}

Background: Spinal tuberculosis is the most common form of extra pulmonary tuberculosis. Complications of untreated spinal tuberculosis include neurological deficit and gibbus deformity. Treatment of spinal TB can be surgical or conservative. Surgical treatment is the mainstay in spinal tuberculosis with neurological deficit. Various approaches to surgical management are anterior only, combined anterior \& posterior and posterior only. Posterior only approach is less traumatic and more familiar to orthopaedicians.

Methods: 23 patients diagnosed of spinal tuberculosis with neurological involvement who underwent single stage posterior decompression and posterior stabilization were analyzed with ASIA grading and VAS score..

Results: The mean age of the study population was 48.86 . There were 12 females and 11 males. The mean operative time and blood loss were 152.19 minutes and $265 \mathrm{ml}$. Increasing age correlated with blood loss and operating time. The mean follow up period was 36.21 months. There were significant differences in the ASIA and the VAS scores when pre-operative, immediate post-op and final follow up where compared.

Conclusions: Single stage posterior decompression and instrumentation is a safe and effective procedure in the treatment of tuberculous spondylodiscitis with neurological deficit and a kyphotic angle $<60^{\circ}$. The long-term results are better because of posterior instrumentation, which provide stability and the healing anteriorly following antituberculous treatment.

Keywords: Spinal tuberculosis, Posterior only approach, Posterior stabilization, Posterior decompression

\section{INTRODUCTION}

Tuberculosis caused by Mycobacterium tuberculosis is a disease that has been present since antiquity. The bacillus affects pulmonary and extra-pulmonary structures. The bone and joint tuberculosis is the most common type of extra-pulmonary tuberculosis and spinal TB is the most common location of extra pulmonary tuberculosis. ${ }^{1}$

The Revised national tuberculosis control programme has done a stellar job of identifying and treating TB. However due to the high disease burden some case of tb spine go on and develop complications such as neurological deficit including paraparesis and paraplegia, severe kyphosis and gibbus formation and cold abscess formation.

The presence of neurological deficit is one of the indications for surgical intervention in TB spine. ${ }^{2}$

Various modalities of intervention such as anterior only, combined anterior plus posterior and posterior only approaches have been advocated each with its own benefits and complications., 
The posterior only approaches have been gaining popularity because of the increased morbidity in using an anterior approach and the frequent need for the use of another specialist surgeon. ${ }^{5}$

This paper is intended to study the effects of single stage posterior stabilization and decompression without bone grafting in Tb spine presenting with a neurological deficit in patients where kyphotic angle is less than $60^{\circ}$.

\section{Aim and objectives}

- To study the effects of single stage posterior stabilization and posterior decompression on patients with tuberculous spondylodiscitis of the spine presenting with a neurological involvement with kyphotic angle less than $60^{\circ}$.

\section{METHODS}

All patients were treated at Saveetha Medical College Hospital between May 2010 to August 2014 were included in the study. This is a retrospective study and all patients fulfilling the inclusion and exclusion criteria were included in the study.

\section{Inclusion criteria}

Inclusion criteria were all patients with people of either sex who are 18 (Eighteen) - 70 (Seventy) years of age; $x$ ray and MRI proven Tuberculosis of the spine with neurological involvement; who appeared for periodic follow-up; people who consented to include themselves in the study.

\section{Exclusion criteria}

Exclusion criteria were tuberculosis of posterior elements alone; tuberculosis with no neurological involvement; pregnant women; kyphosis angle $>60^{\circ}$; patients with an unsound mind (who cannot fill up the questionnaires); patients not willing to consent to the study; previous back surgery; previous fractures of the spine; posterior elements involved in the disease process.

\section{Sample size}

The prevalence in India is about $40 \%$ (which includes latent and active tuberculosis). ${ }^{6}$ Out of this $40 \%, 80 \%$ is considered to be latent and $20 \%$ active. ${ }^{7}$ So active disease is $8 \%$ of the total. $40 \%$ of active tuberculosis is extra pulmonary. ${ }^{8} 10 \%$ of the extra-pulmonary patients have skeletal involvement. (Total: $0.32 \%$ ). Out of this about $50 \%$ have spinal involvement (Total: $0.16 \%)^{9}$

Applying this to formula for calculation of sample size. ${ }^{10}$

Sample size $=\frac{z_{1-\alpha / 2} 2 \mathrm{p}(1-\mathrm{p})}{d^{2}}$
Where $\mathrm{Z} 1_{-\alpha / 2}$ is standard normal variate. 5 (five) $\%$ error value is 1.96

$\mathrm{p}=$ proportion in population: here $\mathrm{p}=0.0016$

$\mathrm{d}=$ absolute error/precision: $\mathrm{d}=0.02$

Hence sample size $=\frac{1.96^{2} \times 0.0016 \times 0.9984}{0.02^{2}}=15.34$

Hence the report of this study may be considered significant

\section{Questionnaires}

Questionnaire's used in the study were Visual Analog Scale - Numerical rating scale and ASIA grading system.

\section{Visual analogue scale}

Numerical rating scale: Visual analogue scale is a patient filled up questionnaire to identify the level of pain in an individual. This is a $10 \mathrm{~cm}$ scale, which has no pain or 0 at one end and 10 or the worst pain of my life at the other end. There are whole numbers such as 1, 2, 3 as intermediate points. ${ }^{11-14}$

The validity, reliability, generalizability and internal consistency have been proven by multiple studies, as is the effectiveness of the scale as a measure of analgesic treatment. $^{15-20}$

This scale has also been proven in multiple studies to be effective for rural illiterate patients as well. ${ }^{21}$

\section{ASIA grading system $^{22,23}$}

The American Spinal injuries association scale (for spinal cord problems) was developed by the American Spinal injuries association. This scale consists of five grades A E (with A being complete Spinal cord injury to E being normal spinal cord function). This grading system has been validated and found to be reliable in assessing spinal cord function in Tb spine. ${ }^{24,25}$

The testing is done for ten muscles on each side of the body and 28 sensory locations on each side of the body.

Sensory examination: The following scores are given to each sensory point

0 - The sensation is absent

1 - The sensation is present but impaired

2 - The sensation is normal

NT - Not testable

Scores are individually tested for both light touch and pin prick sensation. The maximum score possible is 112 . 
Motor examination: The scores used are $0-5$ following the MRC Grading System and in addition NT is not testable. $^{26}$

For the twenty muscles (or ten in the lower limb) a score of $100(50)$ is obtained.

Then the neurological level is identified.

This is then used to classify and grade $\mathrm{A}-\mathrm{E}$

\section{Pre-operative:}

All patients with a diagnosis of Spinal tuberculosis involving the anterior elements and the spinal cord are admitted. Basic investigations such as blood counts, ESR, Mantoux were performed. Co-morbidities were identified and treated appropriately. Necessary opinions taken and patients worked up towards surgical fitness. Antituberculosis treatment begun.

Preoperative VAS and ASIA (AIS) scales obtained.

Figure - 1a Pre-operative $\mathrm{X}$ ray

Figure - 1b Pre-operative MRI

All patients were started on pre operative antituberculous treatment as soon as the diagnosis was made. ${ }^{27}$ The drugs used were a daily regimen of isoniazid $5 \mathrm{mg} / \mathrm{kg}$, rifampicin $10 \mathrm{mg} / \mathrm{kg}$, ethambutol $15 \mathrm{mg} / \mathrm{kg}$, and pyrazinamide $25 \mathrm{mg} / \mathrm{kg}^{28}$

\section{Intra-operative}

Patients operated under General Anasthesia in prone position under sterile aseptic precautions. Levels confirmed under c-arm guidance. Pedicle screw inserted two levels above and below the diseased segment(s).

Posterior decompression: In the diseased segment, either laminectomy, partial laminectomy done to decompress the neural structures.

The process is repeated for each level under c-arm guidance.

If a paravertebral abscess is present it is identified and drained.

Figure $-2 \mathrm{a}$ and $\mathrm{b}$ Intraoperative Picture
Once this is achieved we complete posterior instrumentation using rods and screws. Appropriate rod contouring is performed to restore thoracic kyphosis and lumbar lordosis. Wounds closed in layers over a drain.

Blood loss and operative time calculated.

The pus and the granulation tissue were sent for culture sensitivity to rule out MDR tuberculosis.

\section{Post-operative}

Patients mobilized as tolerated. Aggressive physiotherapy and mobilization performed as needed. DVT prophylaxis instituted. VAS and AIS Scores calculated. Drain removal done on POD 2. Suture removal done on POD 12 if no wound complications were present.

Antitubercular treatment continued as Category I with a total intensive phase of $2 \mathrm{HRZE}$ plus $8 \mathrm{HR}$ for a total period of 10 months ${ }^{38}$ Post-operative ESR measured to identify the status of the disease

\section{Follow-up}

Patients followed up at 1,3,6,12,24 months. X -ray studies done ESR measured. VAS and AIS scores recorded.

Figure 3: Immediate post-operative x-ray.

Figure 4: Follow up $\mathrm{X}$ ray showing healed lesion and no implant failure.

All statistical analyses were performed Microsoft Excel 2011 (Microsoft Inc., USA)

\section{RESULTS}

A total of 23 patients were evaluated in the study. The mean age of the study population was 48.86 (31-65). 11 were males and 12 were females. There is no association between sex and operative time and blood loss $(\mathrm{p}=0.13$ and 0.16 respectively.

Increasing age showed a positive correlation with the blood loss and operating time $(0.20$ and 0.33 respectively) and strong correlation between blood loss and operating time (0.58).

Three patients had type 2 diabetes mellitus, 3 patients had hypertension, 1 patient suffered from Ischaemic heart disease, 1 patient suffered from clinical depression and 2 patients suffered from diabetes and hypertension.

All cases were operated by a single fellowship trained orthopaedic spine surgeon. 
The follow-up period was 28-42 months (mean: 36.21 months).

The VAS obtained was tabulated for pre op, immediate post op and final follow up

The pre-op, immediate post-op and final follow up and final follow up VAS scores were significant when the 3 groups were compared individually and together $(\mathrm{p}<0.00001)$.

Table 1: VAS.

\begin{tabular}{|lllll|}
\hline & Mean & Std dev & Min & Max \\
\hline Preoperative & 6.13 & 1.08 & 4 & 8 \\
\hline $\begin{array}{l}\text { Immediate post } \\
\text { op }\end{array}$ & 3.21 & 1.38 & 1 & 6 \\
\hline Final follow up & 1.21 & 1.17 & 0 & 5 \\
\hline
\end{tabular}

The ASIA score was tabulated for pre op, immediate post op and final follow up.

The pre-op, immediate post-op and final follow up and final follow up ASIA scales were significant when the 3 groups were compared individually and together $(\mathrm{p}<0.0001)$

Table 2: Asia grade.

\begin{tabular}{|llllll|}
\hline & A & B & C & D & E \\
\hline Preoperative & 1 & 8 & 9 & 5 & 0 \\
\hline Immediate post op & 0 & 1 & 5 & 8 & 9 \\
\hline Final follow up & 0 & 0 & 1 & 5 & 17 \\
\hline
\end{tabular}

The average operative time was 152.19 minutes (120-220 minutes). When operating time to complications is compared the operative time of $>180$ minutes is associated with more complications $(\mathrm{p}=0.01)$

Table 3: Operating time.

\begin{tabular}{|ll|}
\hline Mean & 152.1 \\
\hline Std dev & 23.85 \\
\hline Min & 120 \\
\hline Max & 220 \\
\hline
\end{tabular}

The average blood loss was $265.43 \mathrm{ml}$ (160-460 ml). When blood loss is compared to complications there is no significant relationship $(\mathrm{p}=0.34)$

Table 4: Blood loss ( $\mathrm{ml})$.

\begin{tabular}{|ll|}
\hline Mean & 265.43 \\
\hline Std dev & 89.33 \\
\hline Min & 160 \\
\hline Max & 460 \\
\hline
\end{tabular}

The pre-operative ESR was $65.86 \pm 12.64$. The ESR in the immediate postoperative state was $22.39 \pm 8.79$. At the final follow-up ESR was $9.43 \pm 3.56$. The pre-op, immediate post-op and final follow up and final follow up ESR was significant when compared $(\mathrm{p}<0.05$ and $<0.00001$ respectively).

Table 5: ESR.

\begin{tabular}{|lllll|}
\hline & Mean & Std dev & Min & Max \\
\hline Preoperative & 65.86 & 12.64 & 46 & 90 \\
\hline $\begin{array}{l}\text { Immediate post } \\
\text { op }\end{array}$ & 22.39 & 8.79 & 10 & 40 \\
\hline Final follow up & 9.43 & 3.5 & 5 & 18 \\
\hline
\end{tabular}

\section{Complications}

2 patients suffered from superficial infections, which settled down with appropriate antibiotics. 1 patient had deep infection, which necessitated debridement culture sensitivity appropriate antibiotics, and secondary suturing

1 patient developed deep venous thrombosis, which was treated in consultation with vascular surgeon.

Various tests of statistical significance such as the Sign rank test, Fischer's test, chi square test, test for correlation were performed using Microsoft Excel 2011 (Microsoft Inc., USA)

All patients had Tuberculosis confirmed by culture and histo-pathological examination. None of the patients had MDR tuberculosis.

\section{DISCUSSION}

The indication of non-operative treatment of spinal tuberculosis has become crystallized now. ${ }^{1,3,4}$ However the indications of operative management and the type of operative management is still not clear ${ }^{4}$

The different approaches include anterior, anteroloateral approach, posterior approach have their relative merits and demerits.

Studies have shown the need for tailoring the surgical options based on the severity of the disease. ${ }^{29}$

Hodgson advocated the anterior approach in $1960 .^{30}$ Since tuberculosis is predominantly an anterior disease, the anterior approach offered debridement of the disease under direct visualization and direct decompression was achieved. ${ }^{31}$ However the morbidity of anterior surgery is significant because of the need to divide the sternum or the diaphragm. More over the need for an additional specialist surgeon was required. The operative time was longer and this further increased the morbidity. These opinions have been reinforced in multiple further studies. ${ }^{32}$ However anterior approaches are the best when 
a large kyphotic angle is present or a severe gibbus has developed. ${ }^{33,34}$ These cases have been excluded from our study.

The popularity of the posterior approaches has increased following the development of pedicle screw instrumentation. ${ }^{35}$ Many studies proved that the posterior instrumentation provided better results than anterior instrumentation. ${ }^{36,37}$

The type of decompression achieved in the posterior approach is usually indirect. Secondly, although the disease predominantly spares the posterior elements, the laminae are usually removed to achieve decompression. This leads to an iatrogenic instability, which necessitates placing of grafts posterolaterally or a mesh cage with grafts anteriorly to achieve fusion. ${ }^{38}$ Transpedicular decompression has been performed in a few studies, although primarily as an adjunct or as a limited procedure in elderly patients. ${ }^{39,40}$

Our series was designed with this problem in mind. The type of cases, which were included in the series, had neurological deficit and the kyphosis angle was $<60^{\circ}$.

\section{We hypothesized that}

a) The major source of the neurological deficit was the pus and the granulation tissue, which was present anteriorly. Once adequate decompression was achieved leading to decreased pressure, the neural structures would start to function normally.

b) The posterior stabilization was done and the kyphotic angle was corrected, further collapse was prevented and the chemotherapy took care of the infection resulting fusion. This prevented further kyphotic collapse without the need for additional bone grafting.

When the results of this study are analyzed, all 23 patients noticed an improvement in the neurological status, which was statistically significant. 17 of the 23 patients had complete neurological recovery. No one the patients worsened after the surgery. This validates our approach that decompression through posterior approach is sufficient to cause a good neurological recovery and additional posterior decompression may not be required.

Secondly none of the cases in our study group reported loss of fixation or implant failure. This proves that the chemotherapy heals the disease and additional anterior/posterior/posterolateral grafting may not be needed in the included subset of patients.

Thirdly there have been no serious complications or death in our study population. We believe this is in part to the lesser operating time and blood loss when compared to the more radical surgeries.

\section{CONCLUSION}

Single stage posterior decompression and posterior instrumentation is a safe and effective procedure in the treatment of tuberculous spondylodiscitis with neurological deficit and a kyphotic angle $<60^{\circ}$. The longterm results are better because of posterior instrumentation, which provide stability and the healing of anterior structures following antituberculous treatment.

Funding: No funding sources

Conflict of interest: None declared

Ethical approval: Not required

\section{REFERENCES}

1. Tuli SM. Tuberculosis of the Skeletal System. 3rd Ed. New Delhi: Jaypee Brothers Medical Publishers; 2004: 191-194.

2. Jain AK Treatment of tuberculosis of the spine with neurologic deficit Clin Orthop. 2002;398:75-84.

3. Ravindra Kumar Garg and Dilip Singh Somvanshi Spinal tuberculosis: A review J Spinal Cord Med. 2011;34(5):440-54.

4. Anil K Jain Tuberculosis of spine: Research evidence to treatment guidelines Indian J Orthop. 2016;50(1):3-9

5. Benli IT, Acaroglu E, Akalin S, Kis M, Duman E, Un A. Anterior radical debridement and anterior instrumentation in tuberculosis spondylitis. Eur Spine J. 2003;12(2):224-34.

6. WHO, Geneva, 2015 Global Tuberculosis Control 2015, www.who.int/tb/publications/global_report/ Accessed on 18 July 2018.

7. Gupta KB. Challenges in diagnosis and treatment of latent tuberculosis. Indian J Tuberc. 2012;59:1-5.

8. Rama Prakasha S, Suresh G, D'sa IP, Shetty SS, Ganesh Kumar S. Mapping the Pattern and Trends of Extra pulmonary Tuberculosis J Glob Infect Dis. 2013;5(2):54-9.

9. Gautam MP, Karki P, Rijal S, Singh R Pott's spine and paraplegia. J Nepal Med Assoc. 2005;44(159):106-15.

10. Charan J, Biswas T. How to Calculate Sample Size for Different Study Designs in Medical Research? Indian J Psychol Med. 2013;35(2):121-6.

11. McCormack HM, Horne DJL, Sheather S. Clinical applications of visual analogue scales: a critical review Psychol Med. 1988;18:1007-19.

12. DeLoach LJ, Higgins MS, Caplan AB, Stiff JI. The Visual Analog Scale in the Immediate Postoperative Period: Intrasubject Variability and Correlation with a Numeric Scale. Anesth Analg. 1998;86:102-6

13. Downie WW, Leatham PA, Rhind VM, Wright V, branco JA, Anderson JA. Studies with pain rating scales. Annals Rheumatic Dis. 1978;37:378-81

14. Scott J, Huskisson EC. Vertical or horizontal visual analogue scales. Ann Rheum Dis. 1979;38:560.

15. Price DD, McGrath PA, Rafii A, Buckingham B. The validation of visual analogue scales as ratio 
scale measures for chronic and experimental pain. Pain. 1983; 17:45-56.

16. Price DD, Harkins SW. The combined use of visual analogue scales and experimental pain in providing standardized assessment of clinical pain. Clin $\mathbf{J}$ Pain. 1987;3:1-8

17. Wade JB, Price DD, Hamer RM, Schwartz SM, Hart RP. An emotional component analysis of chronic pain, Pain. 1990;40(3):303-10.

18. Harkins SW, Price DD and Braith $\mathrm{J}$ Effects of extraversion and neuroticism on experimental pain, clinical pain and illness behavior. Pain. 1989;36:209-18.

19. Wallenstein SL, Heidrich G, Kaiko R and Houde RW Clinical evaluation of mild analgesics: the measurement of clinical pain. Br J Clin Pharm. 1980;10:319S-27S.

20. Price DD, von der Gruen A, Miller J, Rafii A, Price C. A psychophysical analysis of morphine analgesia. Pain. 1985;22:261-9.

21. Mudgalkar N, Bele SD, Valsangkar S, Bodhare TN, Gorre M. Utility of numerical and visual analog scales for evaluating the post-operative pain in rural patients Indian. J Anaesth. 2012;56(6):553-7.

22. Ditunno JF, Young W, Donovan WH, Creasey G. The International Standards Booklet for Neurological and Functional Classication of Spinal Cord Injury. Paraplegia. 1994;32:70-80.

23. Ditunno JF. Functional assessment in CNS trauma. J Neuro- trauma. 1992;9:S301-5.

24. Julio C. Furlan, Vanessa Noonan, Anoushka Singh and Michael G. Fehlings Assessment of Impairment in Patients with Acute Traumatic Spinal Cord Injury: A Systematic Review of the Literature $\mathrm{J}$ Neurotrauma. 2011;28(8):1445-77.

25. Jain AK, Sinha S. Evaluation of systems of grading of neurological deficit in tuberculosis of spine. Spinal Cord. 2005;43:375-80.

26. https://www.mrc.ac.uk/research/facilities-andresources-for-researchers/mrc-scales/mrc-musclescale. Accessed on 22 July 2018.

27. Toman K. Toman's tuberculosis case detection, monitoring, treatment, 2nd edn. WHO, Geneva; 2004.

28. Treatment of Tuberculosis: Guidelines. 4th edition. Geneva: World Health Organization; 2010.

29. Nussbaum E, Rockswold, GL, Bergman, TA, Erickson, DL, Seljeskog, EL. Spinal tuberculosis: a diagnostic and management challenge. J Neurosurg. 1995;83:243-7.

30. Hodgson A, Stock FE. Anterior Spine Fusion for the Treatment of Tuberculosis of the Spine The
Operative Findings and Results of Treatment in the First One Hundred Cases. The Journal of Bone \& Joint Surgery. 1960; 42(2): 295-310.

31. Hirakawa A, MiyamotoK, Masuda T, Fukuta S; Hosoe $\mathrm{H}$, Iinuma $\mathrm{N}$, et al Surgical outcome of 2stage (posterior and anterior) surgical treatment using spinal instrumentation for tuberculous spondylitis. J Spinal Disorders Techniques. 2010;23(2):133.

32. Garst RJ. Tuberculosis of the spine: a review of 236 operated cases in an underdeveloped region from 1954 to 1964. J Spinal Disord. 1992;5:286-300.

33. Jain AK, Dhammi IK, Saurabh Jain S,Puneet Mishra Kyphosis in spinal tuberculosis - Prevention and correction Indian J Orthop. 2010;44(2):127-36.

34. Rajasekaran S, Shanmugasundaram TK. Prediction of the angle of gibbus deformity in tuberculosis of the spine. J Bone Joint Surg Am. 1987;69:503-9.

35. Zhang HQ, Li JS, Zhao SS, Shao YX, Liu SH, Gao $\mathrm{Q}$, et al. Surgical management for thoracic spinal tuberculosis in the elderly: posterior only versus combined posterior and anterior approaches. Arch Orthop Trauma Surg. 2012;132(12):1717-23.

36. Garg B, Kandwal P, Nagaraja UB, Goswami A, Jayaswal A. Anterior versus posterior procedure for surgical treatment of thoracolumbar tuberculosis: A retrospective analysis Indian J Orthop. 2012; 46(2):165-7.

37. Okada Y, Miyamoto H, Uno K, Sumi MJ. Clinical and radiological outcome of surgery for pyogenic and tuberculous spondylitis: comparisons of surgical techniques and disease types. Neurosurg Spine. 2009;11(5):620-7.

38. Rasouli MR, Mirkoohi M, Vaccaro AR, Yarandi KK, Rahimi-Movaghar V. Spinal Tuberculosis: Diagnosis and Management. Asian Spine J. 2012;6(4):294-308.

39. Lee TC, Lu K, Yang LC, Huang HY, Liang CL. Transpedicular instrumentation as an adjunct in the treatment of thoracolumbar and lumbar spine tuberculosis with early stage bone destruction. J Neurosurg. 1999;91:163-9.

40. He B, Hu Z, Hao J, Liu B. Posterior transpedicular debridement, decompression and instrumentation for thoracic tuberculosis in patients over the age of 60. Arch Orthop Trauma Surg. 2012;132(10):140714.

Cite this article as: Pooswamy SS, Muralidharaogpalan NR. Thoraco lumbar spinal tuberculosis-assessment of functional outcome following posterior decompression and posterior instrumentation. Int J Res Orthop 2019;5:109-14. 